\title{
El buen humor como virtud en la práctica docente
}

\section{Good humor as a virtue in teaching practice}

\author{
María del Socorro Rodríguez Guardado \\ Maestría en Tecnología Educativa \\ Maestría en Pedagogía con especialidad en Docencia Universitaria \\ Correo electrónico: mariadelsocorro.rodriguez@upaep.edu.mx \\ Universidad Autónoma del Estado de Puebla, Puebla, México
}

Recibido: 22 de febrero de 2017. Aprobado: 18 de mayo de 2017

\section{Cómo citar este artículo:}

Rodríguez, M. (2018). El buen humor como virtud en la práctica docente. Espiral, Revista de Docencia e Investigación, $7(2), 43-52$.

\section{Resumen}

Objetivo y tipología textual. De la materia "Ética y liderazgo", que forma parte del currículo del Doctorado en Educación, surge la inquietud de analizar la relación del buen humor, virtud moral en particular tratada por Aristóteles, con la labor docente y debido a la asociación que investigaciones han demostrado sobre el valor positivo del buen humor con la mejora del aprendizaje, el objetivo del presente artículo muestra una reflexión sobre la importancia que tiene considerar esta virtud en la práctica educativa.

Metodología. Desde una visión herméutica-dialéctica se busca dar explicación sobre el significado que tiene el buen humor dentro del aula y de la importancia que tiene la ética positiva del humor para promover, tanto las virtudes morales como las intelectuales. Diversos estudios expuestos por Jáuregui y Fernández (2009); Perandones, Lledó y Herrera (2013); Morreall $(2010,2014)$ y Siuruana (2014) han relacionado el sentido del humor con la disminución de ansiedad, con el ánimo positivo y como promotor de otras virtudes, lo que ha dado pauta para asegurar que el humor debe formar parte integral de cualquier metodología educativa.

Una de las funciones básicas del buen humor es ser una forma de comunicación social y estar conectado al código de cultura social. Profundizar en la investigación de esta virtud en el salón de clase puede abrir puertas para fortalecer la motivación y promover un clima de armonía y cooperación.

Resultados. El humor en la labor docente requiere de criterio, de muchas horas de trabajo y experiencia. Investigaciones han demostrado el valor positivo del buen humor asociándolo al fortalecimiento de las relaciones intrapersonales e interpersonales y como motor para el desarrollo y fortalecimiento de otras virtudes, lo cual deja ver que no pude haber educación sin ética y que a través de las virtudes el ser humano se humaniza.
Palabras clave: Virtud, buen humor, enseñanza, educación.

\section{Abstract}

Objective and textual typology. The "Ethics and leadership" course, part of the curriculum of the PhD in Education, gives origin to the concern for analyzing the relationship between good humor -a moral virtue, treated by Aristotle- and teaching. Due to the positive association between good humor and learning -as evidenced by research- the objective of this article shows a reflection on the importance of this virtue in educational practice.

Methodology. From a hermeneutic-dialectic vision, we seek to explain the meaning of good humor in the classroom and the importance of positive ethics of humor to promote both moral and intellectual virtues. Several studies presented by Jáuregui and Fernández (2009), Perandones, Lledó and Herrera (2013), Morreall $(2010,2014)$ and Siruana $(2013)$ have linked sense of humor to the reduction of anxiety, to positive mood and as a promoter of other virtues, which has given guidelines to ensure that humor should be an integral part of any educational methodology.

One of the basic functions of good humor is to be a form of social communication and to be connected to the code of social culture. Further investigation of this virtue in the classroom can strengthen motivation and promote a climate of harmony and cooperation.

Results. Humor in teaching practice requires good judgment, many hours of work and experience. Research has shown the positive value of good humor associating it with the strengthening of intrapersonal and interpersonal relationships and as an engine for the development and consolidation of other virtues, which shows that there can be no education without ethics and that man is humanized through the virtues.

Keywords: Virtue, good humor, teaching, education. 


\section{Introducción}

Al hacer una reflexión profunda de mi práctica docente, una interiorización con más significado, pude ver que si no hay un ambiente agradable en el aula nada puede aprenderse aún con las estrategias, metodologías y recursos tecnológicos más avanzados. La educación, un tema de mucha seriedad, consiste en introducir al joven al mundo de lo real, su objetivo es formar un hombre nuevo, que actúe cada vez más por sí mismo y que afronte el ambiente solo, es decir, que se eduque al joven con confrontación, con una dimensión cultural que genere compromiso (Giussani, 1992).

Jáuregui y Fernández (2009) mencionan que, en el aula, tanto el docente como el alumno, se enfrentan a desafíos que pueden desembocar en frustraciones, fracaso, tedio, tensión interpersonal, entre muchas más emociones negativas, las cuales pueden estropear la sana convivencia; por lo tanto, el uso adecuado del humor en un salón de clases crea un clima positivo en el que los errores y equivocaciones no implican rechazo, dan paso a que emociones y afectos positivos entren logrando promover la flexibilidad mental, creatividad y otros procesos cognitivos.

Se puede llegar a pensar que el humor, la alegría e inclusive la risa no tienen cabida en el aula, sin embargo, el humor fortalece la motivación, ayuda a la amortiguación de situaciones estresantes y genera un clima de cooperación. Así, Siurana (2014), sintetizando aportaciones de Boskin, Critchley, De Sousa, Hösle y Morreall defiende la ética del humor, porque en ella se critican los vicios de la sociedad, contribuyendo a construir una sociedad más ética, detecta el humor éticamente incorrecto que mantiene estereotipos, ayuda a recoger valores éticos y fomenta el desarrollo de virtudes.

Estudios correlacionales citados por Jáuregui y Fernández (2009) mencionan que el optimismo tiene una relación positiva débil con el sentido del humor como rasgo de personalidad y con las tendencias a emplear el humor para superar situaciones difíciles, como estrategias de afrontamiento. Así también investigaciones han encontrado que las personas expuestas a un estímulo cómico experimentan una mejora en su estado de ánimo, esperanza, mayor interés en una tarea repetitiva y menos ansiedad, ira y tristeza. Perandones, Lledó y Herrera (2013) presentan la investigación que ha demostrado que los miembros de un clima psicológico positivo trabajan mejor para lograr objetivos del colectivo y los docentes con humor generan mayor confianza al trabajar en el aula. Estos autores citan a Zaratustra, personaje fundamental que encarna la síntesis del pensamiento pedagógico de Nietzsche, quien dice que los hombres tienen que aprender a reír.

Sin embargo, todavía son pocos los proyectos de investigación que aluden el valor positivo del humor en la enseñanza. En este escrito se explica el buen humor como una virtud, el significado y la distinción de varias palabras relacionadas con él, la importancia y relación con la práctica docente $y$, finalmente, se presenta la conclusión.

\section{El buen humor: una virtud}

Partiendo de lo dicho por Aristóteles (trad. en 1981), como todo lo que se da en el alma son pasiones, potencias y hábitos, la virtud deberá ser una de estas tres cosas. Se entiende por pasión el deseo, la cólera, el temor, el sentimiento amistoso y en general todas las afecciones a las que son concomitantes el placer o la pena; las potencias son facultades que nos hacen pasibles a esos estados, como son los que hacen capaces de airarnos, contristarnos o compadecernos; los hábitos disposiciones que nos hacen conducirnos bien o mal en lo que respecta a las pasiones; por tanto las virtudes no son pasiones, tampoco potencias, son hábitos por los cuales el hombre realizará bien las obras que le son propias. 


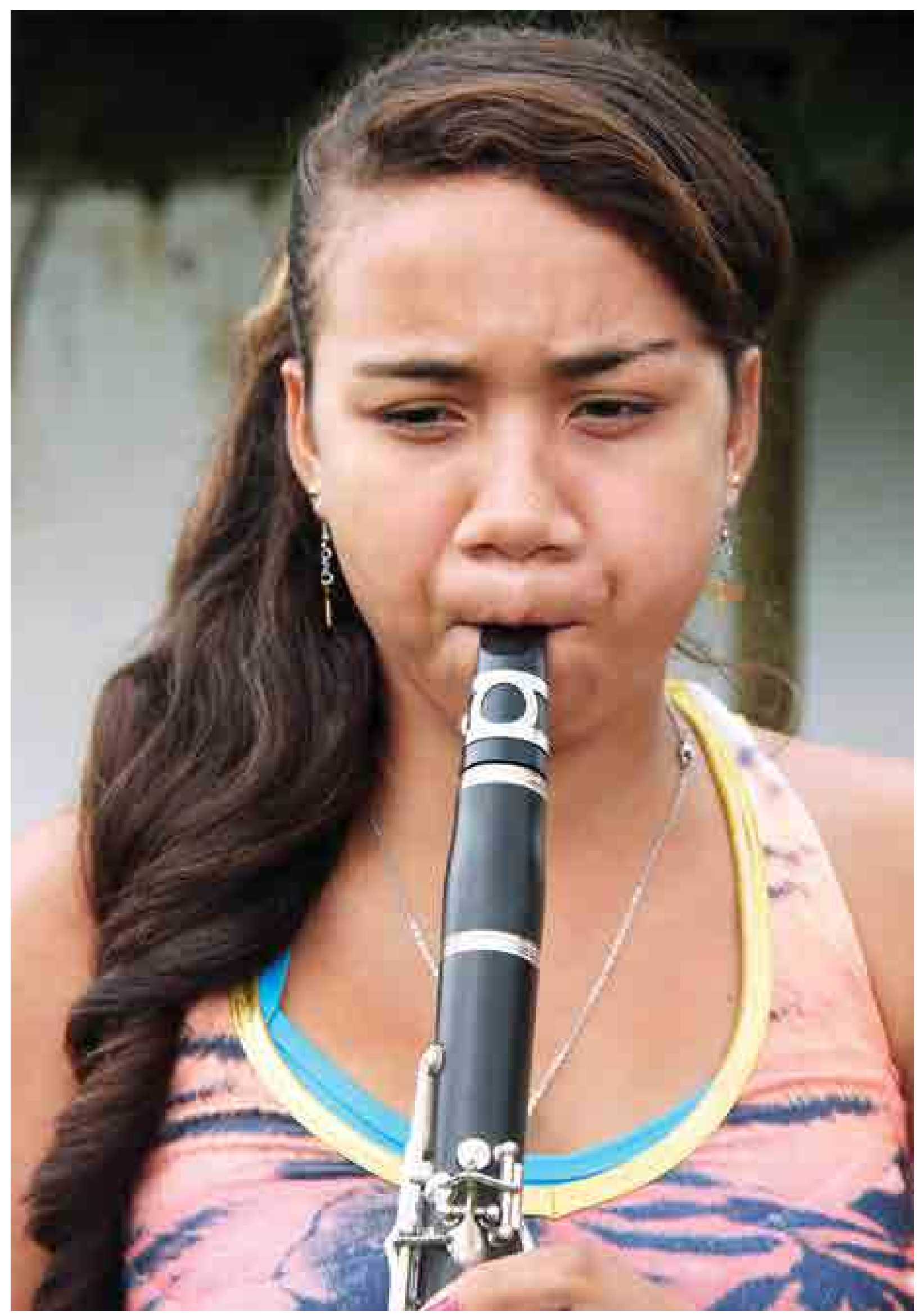


Las virtudes morales no germinan en nosotros naturalmente, somos capaces de recibirlas e irlas perfeccionando; la naturaleza nos da como potencialidad lo que nosotros transformamos en actos que son de tal naturaleza que se malogran, tanto por exceso como por defecto. Aristóteles hace referencia en el libro IV capítulo VIII de la Ética a Nicómaco al buen humor, una de las virtudes morales en particular.

La virtud moral tiene por materia pasiones y acciones. La virtud es una posición intermedia porque apunta al término medio. Así en el sentido del humor, bufones son los que son por exceso y rústicos los que son por defecto, y el término medio pertenece a la cualidad del tacto en las relaciones sociales. La virtud del hombre será entonces aquel hábito por el cual el hombre se hace bueno y gracias al cual realizará bien la obra que le es propia. Aristóteles hace referencia a Platón quien dice: "Es preciso que desde la infancia se nos guíe de tal modo que gocemos o nos contristemos como es menester, y en esto consiste la recta educación" (Aristóteles, trad. en 1981, p. 20).

Siurana (2014) nos aclara que es importante no confundir el humor con la emoción que suscita, ni con la mera expresión de dicha emoción mediante la risa o la sonrisa. La hilaridad es la emoción placentera relacionada con la alegría que se expresa mediante la risa o la sonrisa. El umbral para percibir algo como gracioso y experimentar hilaridad puede variar dependiendo del contexto social, estado de ánimo actual, estado de salud, cansancio, ingestión de alcohol o drogas, y variará dependiendo de nuestra educación ética para reír en el momento oportuno, en el grado correcto y por los motivos justificados. La ética positiva del humor promueve tanto las virtudes intelectuales como las morales, en este sentido, practicar el humor nos llevaría a elevar nuestra altura moral.

Los comentarios de Aristóteles sobre la eutropelia no se tomaron en cuenta hasta la Época Medieval cuando Tomás de Aquino en su obra Suma Teológica los adapta con una posición similar a las del filósofo, afirmando que los seres humanos necesitamos descansar ocasionalmente de la actividad seria. Tomás de Aquino llama a la persona que tiene la virtud moral asociada con el juego y el humor, como agradable con una casta de mente feliz que da a sus palabras y hechos un giro alegre (Siurana, 2014).

Perks (2012) hace referencia sobre la opinión de Platón quien en ocasiones juzgó a la risa de ser violenta, de burla y desprecio. Por parte de los romanos, Cicerón, en su obra Oratore, describe varios métodos por los cuales el ilógico e inesperado puede ser utilizado en el buen humor. El análisis que realizó Perks hace mención a que los teóricos retóricos antiguos eran cautelosos sobre el empleo del buen humor en la comunicación pública.

Para poder adentrarnos a las expresiones que son propias del humor, se explicará cuál es el origen del vocablo "risa", tomando como referencia primaria el Antiguo Testamento donde se establecen dos formas de risa; la sakhaq que tiene un significad o feliz y la iaag, que hace referencia a risa burlona y denigrante. En el griego las palabras para designar este vocablo

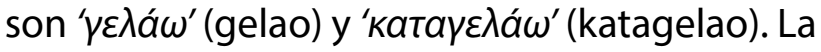
primera se utiliza para el reír de alegría o resplandecer de alegría y la segunda para la risa de aspecto negativo, haciendo alusión a reírse de alguna persona, o burlarse, por eso el prefijo 'ката' (cata) que hace referencia a las cosas que van cayendo (Camacho, 2002).

En el latín no se consideran dos vocablos diferentes, como en el hebreo o en el griego. Del latín 'rīsǔs' es de donde deriva risa y se tiene que hacer la distinción entre una risa positiva y una negativa. Así es como queda establecido que hay una risa buena, feliz, que se relaciona con la alegría y el placer; y por otro lado hay una risa burlona y desenfrenada, aquella mediante la cual el poderoso se ríe del débil y el triunfador del perdedor. 
Así también, al hablar del humor debemos comprender su significado, la relación con la hilaridad, la sonrisa, la risa y la comicidad. Considerando varias aportaciones (Martín, 2003; Siurana, 2014), el humor puede definirse como la capacidad para percibir o mostrar algo que activa la emoción de la hilaridad; siendo la hilaridad la emoción placentera que se relaciona con la alegría y se expresa mediante la risa o la sonrisa. La sonrisa es la expresión física de baja intensidad de la hilaridad (arqueo de labios) y la risa es la expresión de alta o muy alta intensidad de la hilaridad, por último, la comicidad es una cualidad de los seres vivos o cosas que al ser captadas por alguien provoca hilaridad. Para unir los conceptos se puede decir que el humor percibe o muestra algo cómico que provoca hilaridad cuya expresión puede ser de baja, alta o muy alta intensidad.

De acuerdo con Morreall (2014) y Perks (2012) hay tres teorías que pueden explicar el sentido del humor, aunque no existe ninguna teoría aceptada de por qué el humor provoca risa, estos autores hacen referencia a la primera teoría llamada de superioridad, la cual considera la risa como una expresión de los sentimientos que implica una comparación con otros o con algún otro estado de nosotros mismos; argumenta que la risa está involucrada con las burlas de las personas, ideas o instituciones produciendo una elevada autoestima. A veces, nos sentimos superiores a otros y nos podemos reír, pero en ocasiones se presentan situaciones en la vida que pueden causar más llanto que risa.

La teoría de superioridad perdió fuerza y a mediados del siglo XVIII nuevas teorías surgieron; así la segunda teoría es la del alivio, donde la risa se considera como liberación de energía, como si fuera el vapor de una caldera que sale por una válvula, es como si se liberara la emoción contenida. Esta energía nerviosa había sido reprimida por costumbres sociales y autoridades políticas; como ejemplo de la existencia de esta situación Martín (2003) cita el libro El nombre de la rosa de Umberto Eco, novela his- tórica, política, de intriga y suspenso que ocurre en una abadía benedictina, donde el texto envenenado es el manuscrito del segundo libro Poética de Aristóteles, que trata el tema de la comedia y en particular de la risa.

La tercera teoría es la de la incongruencia que de acuerdo con la aportación de Perks (2012) ha sido la más aceptada. Según esta teoría el entretenimiento cómico es una reacción a algo que viola el modelo normal de una persona. Trabaja desde el punto motivacional cognitivo en una situación que implica un evento humorístico o de broma. El primer filósofo en insinuar que el humor está basado en la incongruencia fue Aristóteles, en su obra Retórica nos dice que un modo de provocar la risa de una audiencia es crear una expectativa y luego violarla, lo que ocasiona una decepción que causa risa.

Como un ejemplo de vida es pertinente mencionar a Santo Tomás Moro, quien supo burlarse de sí mismo y cuya vida ejemplar está llena de alegría y buen humor, incluso antes de su muerte en Londres en 1535, al oponerse a las decisiones del Rey Enrique VIII. Fue beatificado por el Papa León XIII en 1886 y canonizado por el Papa Pio XI y el 31 de octubre del 2000 el Papa Juan Pablo II lo proclamó Patrono de los gobernantes y políticos. El último párrafo de su oración del Buen Humor dice: "Dame, Señor, el sentido del humor. Concédeme la gracia de comprender las bromas, para que conozca en la vida un poco de alegría y pueda comunicársela a los demás" (Parroquia de Santo Tomás Moro, s.f).

El sentido del humor suele tener un contexto bastante específico, pero es universal, aunque en cada cultura puede haber códigos diferentes sobre lo que se ríe, por lo que puede decirse que el humor utiliza un lenguaje local. Ronald de Sousa, mencionado por Siurana (2014), basa la ética de la risa defendiendo lo siguiente: "Ríe de lo que es divertido, no te rías de chistes verdes, no te rías de los lisiados (a menos que tú seas uno de ellos) y muestra respeto". El humor tiene un gran potencial para la mejora ética de 
los seres humanos y de las sociedades, pero si se practica incorrectamente puede causar daño, por eso es recomendable la construcción de una "ética del humor".

\section{El buen humor en el salón de clase}

Las aportaciones sumamente valiosas de Arendt y de Maclntyre son expuestas por Higgins (2011); de tal forma que con la teoría de la práctica de Maclntyre se acentúa el camino al cual el trabajo contribuye a nuestra formación ética. A través de la práctica del aprendizaje cultivamos el carácter venciendo deficiencias, aprendiendo percepción yjuicios. Su aportación establece un desarrollo del concepto de virtud dividido en tres fases: la práctica junto con los bienes internos y externos; los modelos de excelencia y las reglas; la segunda que llama orden narrativo de la vida humana y la tercera lo que es una descripción de la vida moral. El valor, la justicia y la honestidad nos acercan a los bienes internos y al producto de excelencia. De este modo para Maclntyre las virtudes son las disposiciones personales que nos ayudan a alcanzar los bienes para ser buenos.

Ser educador es una forma específica de vivir la vocación humana, tipifica la educación como una acción y no es ni de labor, ni trabajo, distinción que marca claramente Arendt, porque la labor la pueden hacer también los animales, porque se refiere a necesidades vitales; en cambio, el trabajo es cuestión del hombre porque pertenece al mundo de la cultura y la acción no tiene mediación de cosas o materia, ya que es el con y para el otro. El humano cumple con las tres dimensiones: labor, trabajo y acción.

Higgins (2011) hace ver que la educación implica el perfeccionamiento moral, y la enseñanza debería ser entendida como una de las prácticas humanas que con mayor claridad nos hace confrontar una tensión existencial fundamental, existimos para nosotros y para otros, pero la educación ha sido rezagada a dos perspectivas, la transmisora, que es la más fácil de vender y la transformativa, la cual genera las preguntas ¿En qué tipo de persona quiero convertirme? y ¿Qué tipo de persona quiero llegar a ser? El profesor debe tener vocación de servicio, darse cuenta que no sabe, buscar respetar y comprometerse a autocultivarse.

Un educador se encuentra en un reto personal y laboral; debe trabajarse personal e interiormente para alcanzar una armonía y conseguir la estabilidad necesaria para realizar con eficiencia su trabajo. El tener autoridad, como menciona Luigi Giussani (1992), es estar muy consciente de la realidad para generar estupor, novedad y respeto, es tener la expresión concreta de la hipótesis de trabajo, el criterio de experimentación de valores que da la tradición, es tener capacidad de comprender y escuchar para después juzgar y afrontar la realidad. El sentido humano nos ayuda a ver el mundo con una mirada amable, generosa y divertida, nos ayuda a poner las cosas en su justa perspectiva (Fernández y García, 2010).

En su libro Un futuro en la garganta: educación para otro mundo posible López Calva (2015) expone una publicación donde hace referencia a los vehículos de significación que Lonergan propone de utilidad para el cambio de la cultura docente. Estos vehículos son medios por los cuales se transforma y reproduce la cultura, los cuales son la intersubjetividad, símbolos, lenguaje, arte y personas; de estos cinco centraré la atención en la intersubjetividad donde la sonrisa tiene una significación de comunicación intersubjetiva.

Lonergan (1988) nos dice que la sonrisa es un conjunto de movimientos variables, ajustado a un esquema, y reconocido como un todo fácilmente perceptible y tiene un objeto; no andamos sonriendo en todo momento ni a todas las personas. Tanto la significación de la sonrisa como el acto de sonreír son naturales y espontáneos. No aprendemos la significación de la sonrisa como lo hacemos con las palabras; las sonrisas tienen una amplia variación 


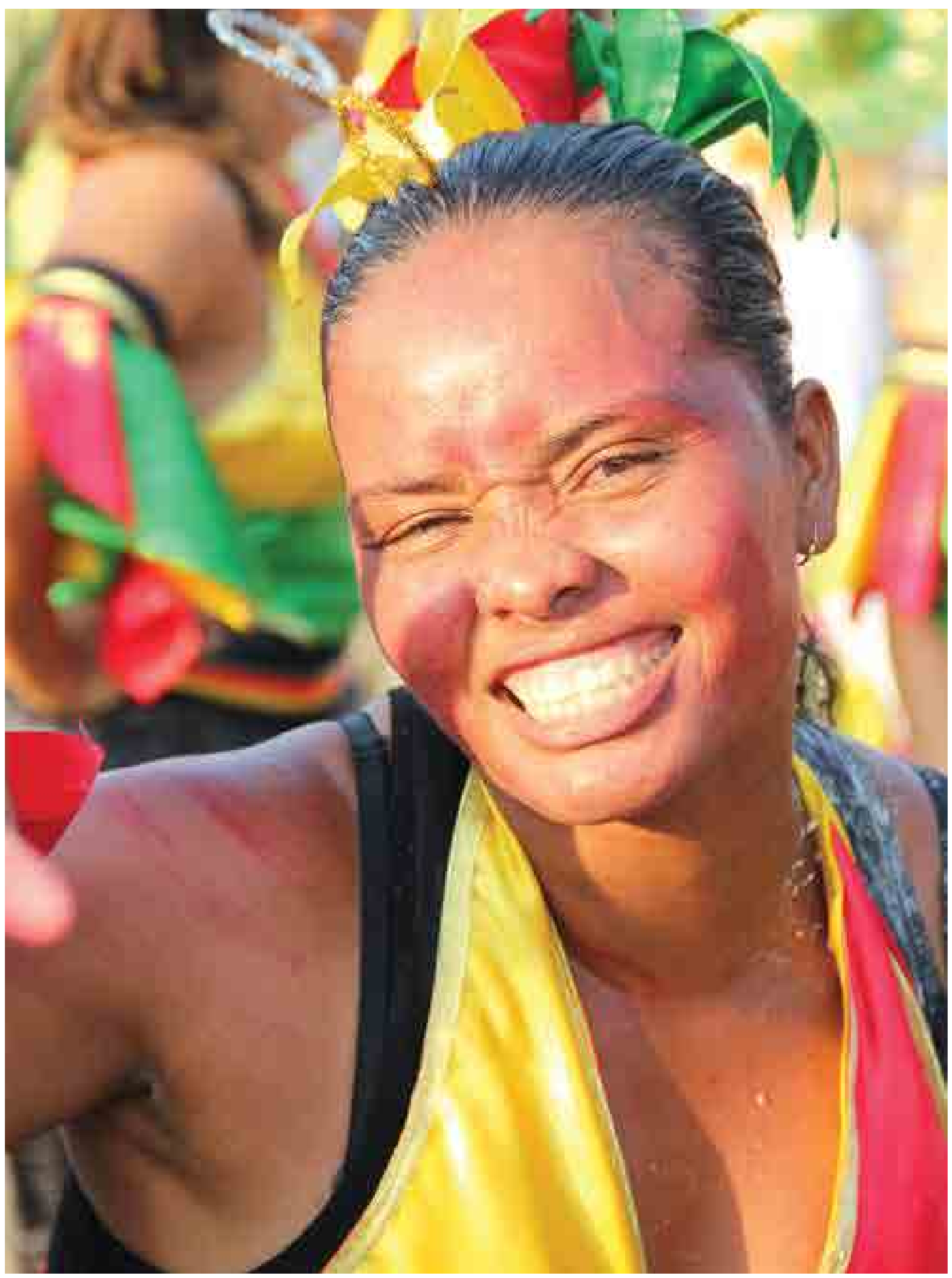


de significados distintos, es subjetiva y el sujeto encarnado en la sonrisa se hace transparente o se oculta.

Una de las funciones básicas del humor es la de ser una forma de comunicación social y está conectado al código de cultura de la sociedad. La risa muestra rasgos de nuestra personalidad y de nuestro carácter. Según experimentos llevados a cabo, después de reír somos más creativos, tomamos mejores decisiones, somos más generosos y nos acercamos más a los demás. La risa es un vehículo de comunicación y una expresión de libertad, ya que el ser humano se siente libre cuando ríe.

El profesorado ejerce influencia en el alumno, no solo por lo que sabe, por lo que transmite o por sus conocimientos, sino también por lo que transmite como persona, de ahí la importancia de que el docente sea modelo de persona positiva, alegre y con sentido del humor. La risa activa el sistema mesolímbico dopaminérgico, un sistema de recompensa que nos obsequia placer (Jáuregui y Fernández, 2009). El sentido del humor es un recurso educativo didáctico que enriquece canales de comunicación, enriquece los procesos enseñanza-aprendizaje facilitando que los aprendizajes sean más significativos y eficaces.

El sentido del humor debe ser siempre en sentido constructivo. Si entramos en el aula llenos de temores, mostrando una autoridad con un comportamiento hostil para imponer un aparente respeto, el ambiente se vuelve tenso, las relaciones interpersonales distantes y se pude caer en el tedio. Sin embargo, no hay que confundir la disciplina y el orden en el aula con algo hostil, porque los límites y las normas deben favorecer siempre un ambiente de trabajo. El humor debe formar parte integral de cualquier metodología educativa. La alegría va unida al amor y no hay vocación sin amor (Perandones, et al., 2013).
La risa es placentera y acompaña el juego, es como una recompensa emocional que estimula al niño. Una clase en la que prolifera la risa y las emociones positivas, es un lugar en el que se apetece estar, aprender y prestar atención, o en el caso del profesor, el trabajar y enseñar. El humor positivo es afiliativo, considera las bromas para hacer reír a los demás disminuyendo el estrés; es auto afirmante porque provoca risa de las incongruencias de la vida y se emplea como mecanismo de regulación emocional (Jáuregui y Fernández, 2009). El humor agresivo y destructivo puede tener efectos muy nocivos sobre la salud mental. Esta clase de humor ridiculiza provocando la risa a costa de alguien; es autodestructivo al causar la risa de uno mismo para caer bien a los demás.

Se comparte la aportación de Morreall $(2010,2014)$ y Siurana (2014) al decir que el sentido del humor promueve otras virtudes, de tal modo que al desear que las cosas ocurran en el momento y en el tiempo que queremos, viendo las cosas con humor somos capaces de mantener la paciencia. El ver las cosas de diferente manera es señal de una mente abierta, se favorece el entendimiento con otras personas, se reducen las fricciones y de esta forma se es tolerante.

La amabilidad se deja ver cuando a las personas se les corrige con gracia, sin regaños en vez de adoptar una forma malhumorada. Hay que aceptar los errores, el reírse de sí mismo muestra el lado humano y hace reconocer que se está lejos de ser perfectos y la humildad se hace presente. En ocasiones la frustración aparece en las actividades diarias, pero al combinar la paciencia con la humildad es más fácil superar los obstáculos. El coraje para salir adelante pone a la vista la perseverancia.

La tarea educativa es comunicativa, de intercambio continuo de ideas, conocimiento, emociones y comportamientos. Si una persona ríe se encontrará más disponible para ayudar; 


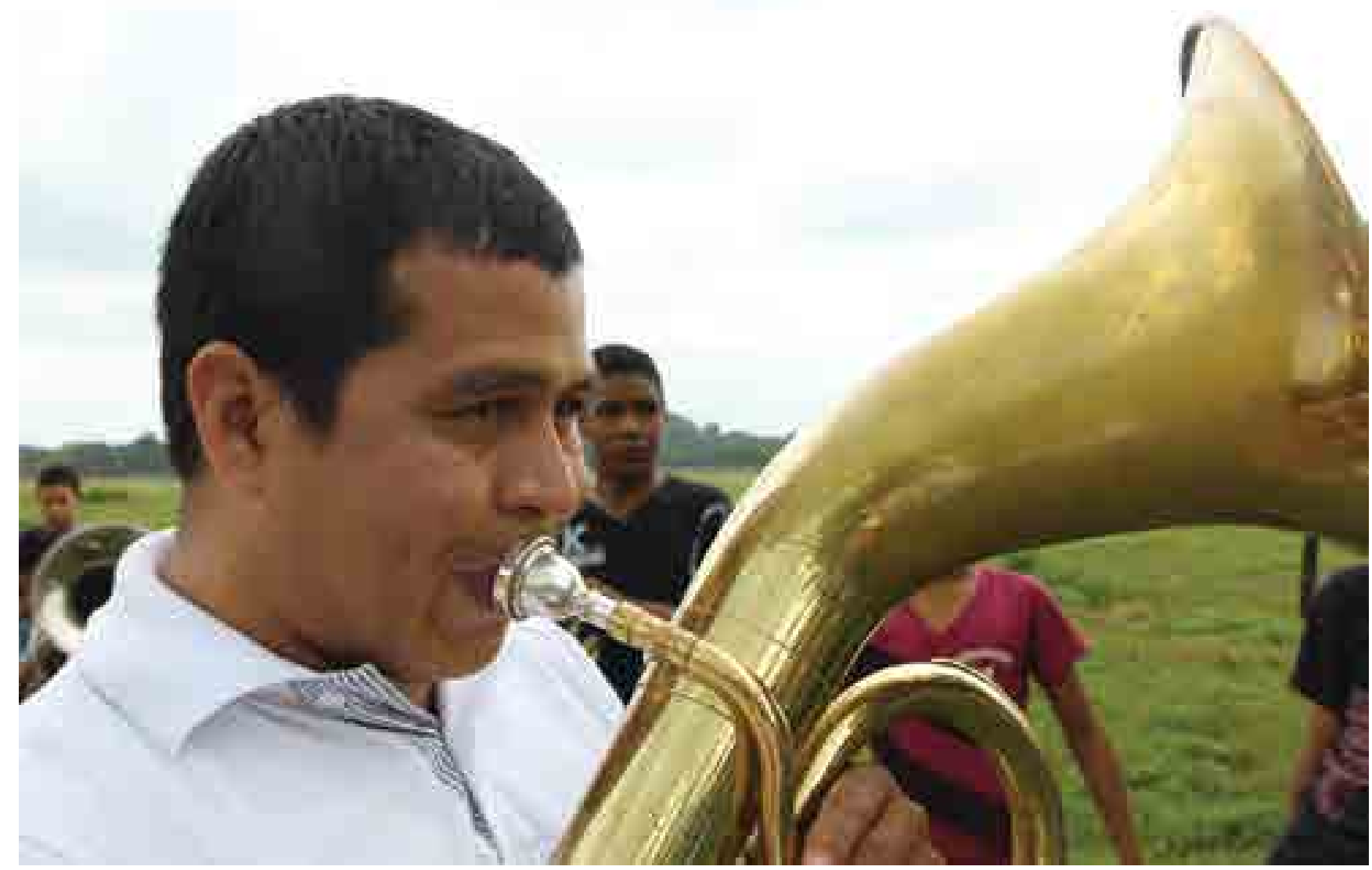

la risa no solo nos acerca, sino que nos vuelve más generosos con los demás.

\section{Conclusión}

Quienes han tomado la decisión de dedicar su labor, trabajo y acción a la educación tienen el compromiso de abrir perspectivas a otras personas, ejercer una profesión de ayuda que implica un perfeccionamiento moral. Ser profesores, docentes, maestros, pero más que todo ser también alumnos de los educandos. En este escrito se presentó una breve investigación sobre una de las virtudes que es tratada en la Ética Nicomáquea de Aristóteles. Las virtudes, como ya se mencionó, son hábitos, son disposiciones personales que ayudan a alcanzar bienes. La elección de una virtud para elaborar el trabajo no fue fácil, sin embargo, se pudo constatar que no se desarrollan las virtudes de manera individual porque todas forman parte de una intersección, de tal modo que una implica el desarrollo o el fortalecimiento de otras.
Conocer las palabras que se implican (hilaridad, sonrisa, risa, comicidad) y las teorías por las cuales se intenta dar una explicación del porqué del sentido del humor ponen en evidencia la importancia que ha tenido desde tiempo atrás su estudio. Así se aprecia que del sentido del humor se desprenden muchas virtudes (Morreall, 2009, 2010) y Siurana (2014) nos hace ver que el humor desempeña tanto una función terapéutica como crítica y brinda la oportunidad de darse cuenta que las cosas pueden verse de otra manera.

Considerar la implementación del buen humor en el salón de clase es muy probable que genere el fortalecimiento de la motivación, lime situaciones estresantes y favorezca un clima de cooperación; de esta forma se puede cuestionar si el ser serio, hostil, hablar con tono cortante puede promover la autoridad, el orden, la disciplina y el aprendizaje. Los investigadores y expertos en el tema, citados en el cuerpo del 
escrito, coinciden en comentar que en el aula no puede captarse la atención ni el interés si no se transmite alegría, y siendo la escuela un lugar de encuentro, de convivencia social como primera instancia, debe predominar un clima de armonía y de respeto donde se aprende unos de otros. El uso del humor agresivo, especialmente el que pone en ridículo al alumno, se asocia con evaluaciones peores, y hace que los estudiantes sean inhibidos y conformistas, tengan más miedo al fracaso y toleren menos riesgos.

El humor en la labor docente requiere de criterio, muchas horas de trabajo y de experiencia. Hay que tener en cuenta que es un tema bastante serio, que no cualquiera lo domina y que el trabajo como docentes es aprenderlo para también enseñarlo, sin olvidar que es una virtud que al practicarla hará mejores personas y de esta forma dará un giro positivo a esta práctica tan noble y tan humana que es la educación.

\section{Referencias}

Aristóteles. (1981). Ética Nicomáquea-política. (Trad. Antonio Gómez Robledo, 9a ed.). México: Porrúa.

Camacho, J.M. (2002). La risa y el humor en la antigüedad. Recuperado de http://www.fundacionforo.com/pdfs/ archivo14.pdf
Fernández, S.J.D., y García, C.J. (2010). El valor pedagógico del humor en la educación social. España: Desclée de Brouwer.

Giussani, L. (1992). Educar es un riesgo. España: Encuentro Ediciones.

Higgins, C. (2011). The Good Life of Teaching. An ethics of Profesional Practice. London: Wiley-Blackwell.

Jáuregui, N.E., Fernández, S.J.D. (2009). Risa y aprendizaje: el papel del humor en la labor docente. Revista Interuniversitaria de Formación del Profesorado, 66(23,3), 203-215.

López Calva J. M. (2015). Con un futuro en la garganta. Educación para otro mundo posible. México: Universidad Iberoamericana Puebla.

Lonergan, B. (1988). Método en Teología. Salamanca: Editorial Sígueme.

Martín, C.J. (2003). La risa y el humor en la antigüedad. Recuperado de www.fundacionforo.con/pdfs/archivo14.pdf

Morreall, J. (2010). Comic Vices and Comic Virtues. International Journal of Humor Research, 23(1), 1-26.

Morreall, J. (2014). Humor, Philosophy and Education. Educational Philosophy and Theory, 46(2), 120-131.

Parroquia de Santo Tomás Moro (s.f). Oración del Buen Humor. Recuperado de http://www.parroquiasantotomasmoro.com

Perandones, G.M.T., Lledó, C.A., y Herrera, T.L. (2013). ¡Sonría maestro; Aprendizaje sentido. Con humor la letra entra mejor. Revista de Educación y Humanidades. DEDICA, 4, 17-186.

Perks, L. (2012). The Ancient Roots fo Humor Theory. The International Journal of Humor Research, 25(2), 119-132.

Siurana, J.C. (2014). Ética del humor y diversidad cultural. Dilemata, 15, 215-231. 